\title{
Perbandingan Induction Hardening dengan Flame Hardening pada Sifat Fisik Baja ST 60
}

\author{
Iswanto $^{1}$, Edi Widodo ${ }^{2}$, Ali Akbar ${ }^{1}$, Angga Kharisma Putra ${ }^{1}$ \\ 1 Teknik Mesin, Universitas Muhammadiyah Sidoarjo \\ 2 Teknik Mesin, Universitas Brawijaya Malang \\ e-mail address : iswanto@umsida.ac.id
}

\section{Keywords:}

Induction hardening; flame hardening; tensile strength; micro structure; ST 60 steel

\section{PENDAHULUAN}

Teknik pemanasan logam adalah sebuah proses yang digunakan guna meningkatkan sifat keuletan dan kinerja dari sebuah material atau komponen [1, 2]. Kerusakan sebuah material umumnya diawali dari kerusakan di bagian permukaan material yang dikarenakan oleh adanya faktor lingkungan yang mempengaruhi seperti korosi, maupun keausan yang diakibatkan oleh interaksi dengan komponen yang lain [3]. Dalam bidang industri, lebih khusus industri yang bergerak dalam bidang permesinan, teknik pemanasan logam sangat diperlukan untuk dapat menghasilkan sebuah peralatan atau komponen yang mempunyai daya tahan terhadap korosi, serta memiliki daya tahan terhadap keausan yang diakibatkan oleh gesekan dengan komponen lain, sehingga umur pakai komponen akan meningkat dengan sendirinya [4]. Berbagai metode dilakukan agar dapat memperbaiki kualitas permukaan dari sebuah material, sesuai dengan keperluan produk yang diharapkan [5].

Dalam hal rekayasa material, metode pemanasan logam yang lebih dikenal dengan istilah perlakuan permukaan (surface treatment). Secara umum perlakuan permukaan bisa dilaksanakan dengan dua cara. Pertama dengan melakukan pengubahan fasa atau mengubah struktur kristal yang ada dalam material. Kedua, dengan melakukan pengubahan komposisi kimia pada permukaan sebuah material (menambahkan unsur-unsur kimia yang lain lain dalam komposisi material) $[6,7]$. Proses pengubahan struktur kristal ini dilakukan dengan jalan memanaskan spesimen pada suhu tertentu dan kemudian dilakukan pendinginan cepat (quench) agar mendapatkan struktur kristal yang di inginkan. Beberapa cara/metode surface treatment yang biasa digunakan adalah karburasi (carburizing), karbonitridasi (carbonitriding), nitridasi (nitriding), induksi listrik (induction hardening) dan nyala api (flame hardening) [6].

Induction hardening adalah proses pemanasan dengan memakai prinsip kumparan yang diberi aliran arus bolak-balik dan diletakkan didekat bahan konduktif [8]. Material konduktif dan kumparan selanjutnya menghasilkan medan magnet bolak-balik dan mengakibatkan arus eddy. Panas yang timbul pada material konduktif diakibatkan oleh aliran arus eddy yang berada disekitar material konduktif tersebut [9].

Flame hardening adalah proses pengerasan permukaan untuk mengeras hingga beberapa kedalaman di bawah permukaannya 
dari komponen baja untuk menahan abrasi dan aus dengan ketangguhan yang wajar dari inti yang tidak dipanaskan meningkatkan kelelahan, tekukan dan kekuatan puntir [10, 11]. Dalam proses ini, permukaan logam dipanaskan untuk waktu yang cukup sehingga dapat menaikkan suhu dengan cepat di atas suhu kritis atas dengan menggunakan nyala oksi-asetilena netral [12].

Pada penelitian ini akan membandingkan sifat fisik baja ST 60 yang mendapat perlakuan induksi hardening dengan baja ST 60 yang diberikan perlakuan flame hardening. Sifat fisik yang diuji adalah kekuatan tarik dan struktur mikro.

\section{METODOLOGI PENELITIAN}

Pada penelitian ini peralatan yang digunakan adalah mesin induction hardening dan mesin flame hardening (mesin las asetelin) yang digunakan untuk melakukan proses pemanasan spesimen. Mesin bubut digunakan untuk membuat spesimen uji tarik. Untuk mengukur suhu ketika proses pemanasan spesimen digunakan thermometer infrared. Spesimen yang akan diuji adalah baja ST60 dan diuji menggunakan mesin uji tarik model GAG5051-PC. Pengamatan struktur mikro menggunakan mikroskop metalurgi merek Epiphot-300.

Langkah pertama yang dilakukan pada penelitian ini adalah menyiapkan alat dan bahan yang dibutuhkan. Selanjutnya memotong dan membubut baja ST60 sebagai benda uji dengan ukuran sesuai dengan standart ASTM. Kemudian melakukan proses pemanasan terhadap benda uji dengan mesin induction hardening sebanyak tiga buah, seperti pada gambar 1.

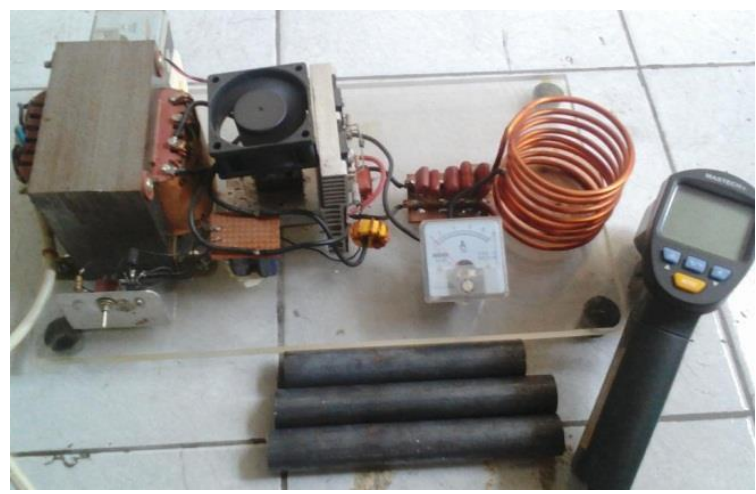

Gambar 1. Proses pemanasan dengan mesin induction hardening

Berikutnya melakukan proses pemanasan terhadap benda uji dengan mesin flame hardening (mesin las aseteline) sebanyak tiga buah, seperti pada gambar 2 .

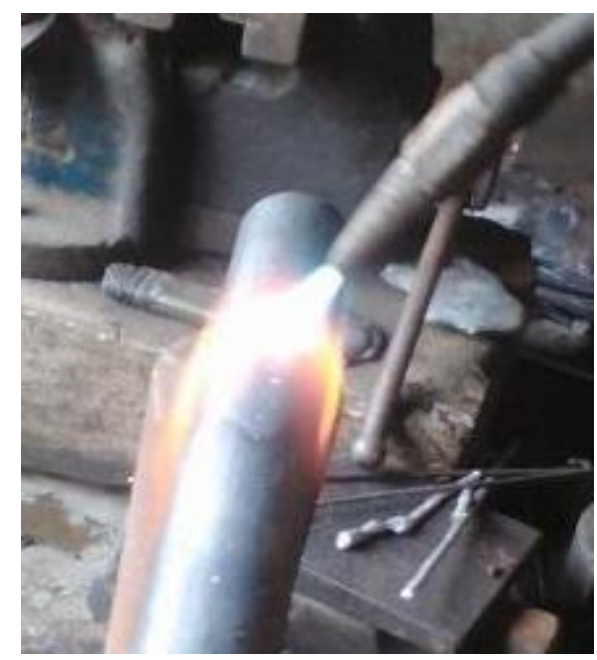

Gambar 2. Proses pemanasan dengan mesin flame hardening

Setelah proses pemanasan mencapai pada suhu yang telah ditentukan, kemudian dilakukan proses pendinginan dengan menggunakan media air. Langkah berikutnya adalah melakukan pengujian tarik terhadap benda uji yang telah disiapkan dan yang terakhir adalah melakukan pengamatan terhadap struktur mikro (melakukan uji mikrostruktur).

\section{HASIL DAN PEMBAHASAN}

\section{Hasil Uji Tarik}

Setelah dilakukan pengujian tarik terhadap spesimen hasil pemanasan menggunakan induksi dan pemanasan 
menggunakan flame, maka diperoleh data seperti pada tabel 1 .

Table 1. Hasil pengujian tarik spesimen dengan induction hardening dan flame hardening

Pemanasan Temperatur Kekuatan Tarik Regangan

\begin{tabular}{lccc} 
& $\left({ }^{\circ} \mathrm{C}\right)$ & $\left(\mathrm{N} / \mathrm{mm}^{2}\right)$ & $(\%)$ \\
\hline $\begin{array}{l}\text { Induction } \\
\text { Hardening }\end{array}$ & & 87.15 & 17.5 \\
$\begin{array}{l}\text { Flame } \\
\text { Hardening }\end{array}$ & 650 & & \\
\hline
\end{tabular}

Dari hasil pengujian tarik terhadap spesimen hasil pemanasan induksi, dari mulai gaya diberikan sampai dengan spesimen patah diperoleh grafik tegangan dan regangan seperti dsajikan pada gambar 3 .

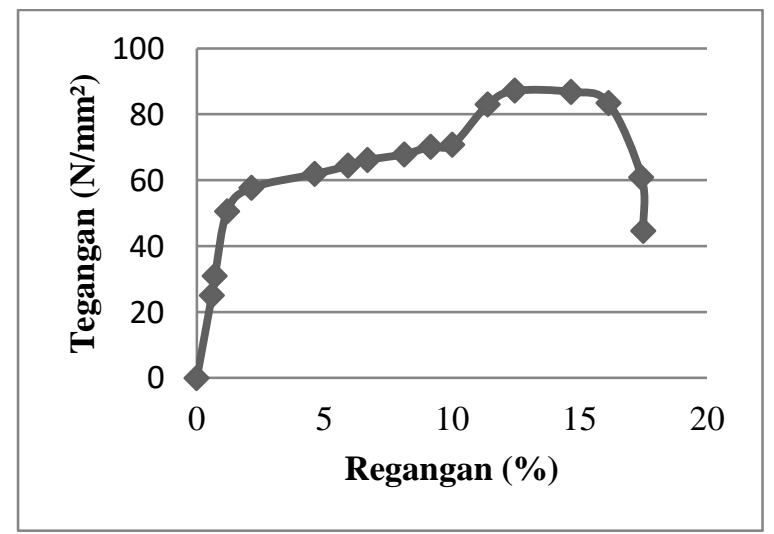

Gambar 3. Grafik tegangan dan regangan spesimen dengan induction hardening

Sedangkan dari data pengujian tarik pada spesimen hasil pemanasan flame, mulai saat diberikan gaya terhadap spesimen sampai dengan spesimen patah diperoleh grafik tegangan dan regangan seperti terlihat pada gambar 4.

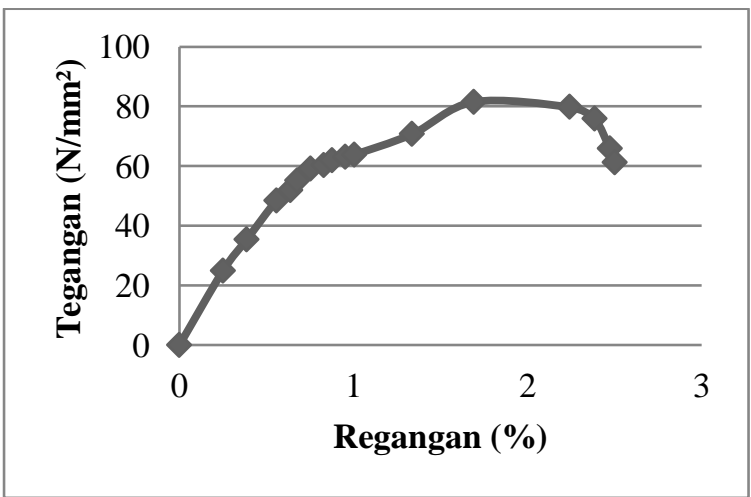

Gambar 4. Grafik tegangan dan regangan spesimen dengan flame hardening

Dari table 1 dan gambar 3 serta gambar 4 dapat dilihat bahwa baja ST 60 dengan perlakuan induction hardening memiliki kekuatan tarik lebih tinggi yaitu sebesar 87,15 $\mathrm{N} / \mathrm{mm}^{2}$ dibandingkan dengan baja ST 60 yang mendapat perlakuan flame hardening yang hanya sebesar $81,53 \mathrm{~N} / \mathrm{mm}^{2}$. Begitu juga jika dilihat dari ragangannya, baja ST 60 yang memperoleh perlakuan induction hardening memiliki ragangan lebih tinggi yaitu sebesar $17,5 \%$, dari pada baja ST 60 yang diberi perlakuan flame hardening yang hanya 2,5\%.

Pada penelitian ini waktu yang dibutuhkan untuk mencapai suhu $650 \mathrm{C}$ pada spesimen dari proses induction hardening dan flame hardening berbeda. Untuk mencapai suhu $650 \mathrm{C}$ pada spesimen, dibutuhkan waktu 55 menit apabila menggunakan induction hardening, dan jika menggunakan flame hardening membutuhkan waktu 2,25 menit. Sehingga pada proses induction hardening spesimen mengalami pemanasan lebih lama meskipun suhu tertingginya sama yaitu $650 \mathrm{C}$. Hal ini menyebabkan perlakuan induction hardening pada baja ST 60 memiliki kekuatan tarik dan modulus elastisitas lebih tinggi dibandingkan dengan perlakuan flame hardening.

\section{Hasil Pengamatan Struktur Mikro}

Hasil dari pengamatan struktur mikro pada baja ST 60 dengan perlakuan induction hardening dan flame hardening dapat dilihat pada gambar 5 dan 6.

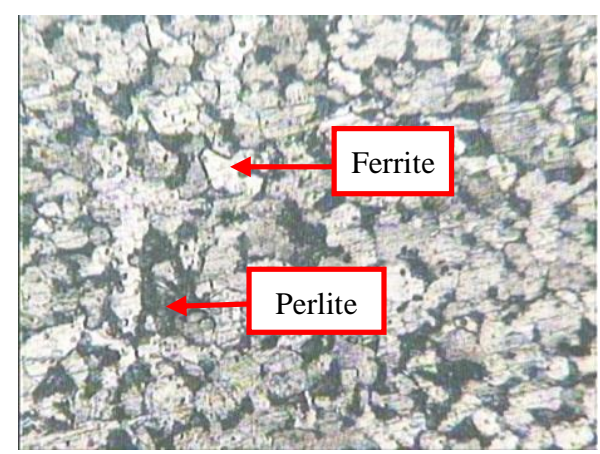

Gambar 5. Struktur mikro baja ST 60 dengan perlakuan induction hardening 


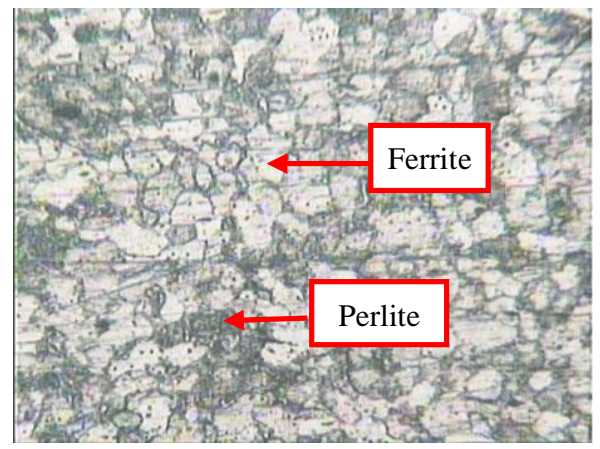

Gambar 6. Struktur mikro baja ST 60 dengan perlakuan flame hardening

Dari gambar 5 dan 6 dapat dijelaskan bahwa: baja ST 60 yang mendapat perlakuan induction hardening yang ditunjukkan oleh gambar 5, memiliki butiran perlite (warna hitam) lebih banyak dan lebih jelas (berwarna lebih hitam) dibandingkan dengan baja ST 60 yang menerima perlakuan flame hardening, yang ditunjukkan pada gambar 6. Butiran perlite yang jumlahnya lebih banyak dan warnanya lebih hitam ini disebabkan oleh pemanasan pada induction hardening waktunya lebih lama dibandingkan dengan flame hardening. Karena pada perlakuan induction hardening menghasilkan butiran perlite dengan jumlah yang lebih banyak dan warnanya lebih hitam maka hal ini menyebabkan kekuatan tarik baja ST 60 semakin tinggi.

\section{KESIMPULAN}

Dari penelitian yang telah dilakukan tentang perbandingan induction hardening dengan flame hardening pada sifat fisik baja ST 60 dapat disimpulkan bahwa:

1. Baja ST 60 dengan perlakuan induction hardening memiliki kekuatan tarik lebih besar yaitu sebesar 87,15 N/mm2 dibandingkan baja ST 60 yang diberikan perlakuan flame hardening dengan kekuatan tarik $81.53 \mathrm{~N} / \mathrm{mm}^{2}$.

2. Besarnya regangan baja ST 60 dengan perlakuan induction hardening senilai 17,5 $\%$, sehingga lebih besar dibanding baja ST 60 yang mendapat perlakuan flame hardening yang besar regangannya hanya $2.5 \%$.
3. Dari pengamatan struktur mikro, baja ST 60 dengan perlakuan induction hardening lebih banyak menghasilkan butiran perlite dibandingkan dengan perlakuan flame hardening.

\section{REFERENSI}

[1] H. Kristoffersen and P. Vomacka, "Influence of process parameters for induction hardening on residual stresses," Mater. Des., vol. 22, no. 8, pp. 637-644, 2001.

[2] S. O. Seidu, and B. J. Kutelu, "Influence of heat treatment on the microstructure and hardness property of inoculated grey cast iron," International Journal of Engineering and Technology, vol. 3, no. 9, pp. 888-892, 2013.

[3] Y. Totik, R. Sadeler, H. Altun, and M. Gavgali, "The effects of induction hardening on wear properties of AISI 4140 steel in dry sliding conditions," Mater. Des., vol. 24, no. 1, pp. 25-30, 2003.

[4] M. K. Lee, G. H. Kim, K. H. Kim, and W. W. Kim, "Effects of the surface temperature and cooling rate on the residual stresses in a flame hardening of $12 \mathrm{Cr}$ steel," J. Mater. Process. Technol., vol. 176, no. 1-3, pp. 140-145, 2006.

[5] S. Zhu, Z. Wang, X. Qin, H. Mao, and K. Gao, Theoretical and experimental analysis of two-pass spot continual induction hardening of AISI 1045 steel, vol. 229. Elsevier B.V., 2016.

[6] ASM International Handbook Committee, "Volume 4, Heat Treating," American Society for Metals International, 1991.

[7] A. Vieweg et al., "Induction hardening: Differences to a conventional heat treatment process and optimization of its parameters," IOP Conf. Ser. Mater. Sci. Eng., vol. 119, no. 1, 2016.

[8] K. Gao, X. Qin, Z. Wang, and S. Zhu, "Effect of spot continual induction hardening on the microstructure of steels: Comparison between AISI 1045 and 5140 steels," Mater. Sci. Eng. A, vol. 651, pp. 535-547, 2016.

[9] W. P. Raharjo and B. Kusharjanta, "Rancang Bangun Pemanas Induksi Berkapasitas 600 W untuk Proses Perlakuan Panas dan Perlakuan Permukaan," Pros. SNST ke-4, pp. 207-215, 2013.

[10] S. Jeyaraj, K. Arulshri, K. Harshavardhan, and P. Sivasakthivel, "Optimization of Flame Hardening Process Parameters Using L9 Orthogonal Array of Taguchi Approach," Int. J. Eng. Appl. Sci., vol. 2, no. 3, p. 257976, 2015. 
[11] K. S. M. SABARINATH. L, "Effect of Flame Hardening and Various Quenching Medium on the Mechanical and Metallurgical Properties of Grey Cast Iron Lathe Bed," Int. J. Adv. Sci. Res. Eng., vol. 2, no. 7, pp. 1-7, 2016.

[12] S. Talapatra, G. Kibria, A. M. M. N. Ahsan, and T. Bhowmick, "MIE12-043 Effect of Flame Hardening on High Carbon Steel Forging," pp. 1-4, 2013. 